\title{
Consórcios intermunicipais para a destinação de RSU em aterros regionais: estudo prospectivo para os municípios no Estado do Paraná
}

\author{
Intermunicipal trusts with regional landfills for urban solid waste disposal: \\ a prospect study for the municipalities in the state of Paraná, Brazil
}

\begin{abstract}
Juliana Akiko Noguchi Suzuki
Engenheira Ambiental formada pela Pontifícia Universidade Católica do Paraná (PUC-PR). Trabalhou na Superintendência de Desenvolvimento de Recursos Hídricos e Saneamento Ambiental (SUDERHSA) de out/2006 a jan/2008. Especialista em Políticas Públicas e Gestão Governamental.

\section{João Gomes}

Engenheiro Ambiental formado pela Universidade do Tocantins (Unitins). Trabalhou na SUDERHSA de abril a outubro de 2006. Engenheiro ambiental da Unidade de Recursos Hídricos da Companhia de Saneamento do Paraná (Sanepar).
\end{abstract}

\begin{abstract}
Resumo
O estudo prospectivo teve como objetivo identificar grupos de municípios com potencial para formação de consórcios intermunicipais, visando à destinação final adequada dos resíduos sólidos urbanos dos municípios consorciados. O estudo levou em consideração dados populacionais, sistema viário, localização geográfica da sede urbana e bacia hidrográfica na qual está inserida. Dentre as vantagens da formação de consórcios, pode-se citar: a redução do número de áreas utilizadas, como aterros, ganhos de escala possibilitando a profissionalização da sua operação e concentração das ações de fiscalização ambiental. Dos 399 municípios do Estado do Paraná, 377 foram agrupados em 58 consórcios intermunicipais, compreendendo 97,3\% da população urbana total do Estado. Apresentam-se aqui as diretrizes, os critérios de planejamento e os resultados obtidos, discutindo os fatores que poderão influenciar a implantação do modelo.
\end{abstract}

Palavras-chave: consórcios intermunicipais; resíduos sólidos urbanos; destinação final; aterros sanitários.

\begin{abstract}
The goal of this prospective study was to identify, to analyze and to map groups of municipalities that could form intermunicipal trusts with the purpose of disposing the municipal solid waste generated internally in regional landfills to be located within the trust's territory. The variables considered were urban population, road system, geographical location of the urban centers and water basin divisions. Among the advantages of constituting such trusts are: the reduction of areas used as landfills, the increase in scale allowing the hiring of professional landfill operation service and the concentration of environmental inspection actions. As a result, 377 from the 399 municipalities in the State of Paraná were divided into 58 intermunicipal trusts, comprehending $97,3 \%$ of the urban population of the State. This article also presents the methodology applied and the factors that could influence its implementation.
\end{abstract}

Keywords: environmental planning; intermunicipal trusts; municipal solid waste disposal; landfills.

\section{Introdução}

A destinação final adequada dos resíduos sólidos urbanos (RSU) no Brasil ainda deixa a desejar. Em 2002, apenas 22,3\% dos municípios brasileiros destinavam seus resíduos em aterros sanitários, $47,1 \%$ em aterros controlados e 30,5\% em lixões (IBGE).

A implantação de mais aterros sanitários não resolve o problema. Não só a gestão dos resíduos sólidos urbanos compõe-se de outras etapas além da destinação final - reciclagem e educação ambiental, por exemplo - como também a correta operação do aterro é essencial para assegurar o aproveitamento da totalidade de sua vida útil e evitar que se torne um foco de contaminação ambiental.

Um aterro construído com recursos públicos pode facilmente tornar-se um novo lixão, caso sua operação não seja feita de maneira adequada. Por isso, a correta operação dos aterros sanitários existentes é um nó crítico no gerenciamento dos RSU, sendo que a ação conjunta e coordenada entre municípios pode viabilizar ganhos ambientais e econômicos na provisão desses serviços públicos. A lei federal 
11.107/2005, que dispõe sobre a contratação de consórcios públicos, e o decreto 6.017/2007 (BRASIL, 2007), que a regulamenta, criaram o arcabouço legal para adoção do consórcio público intermunicipal como figura jurídica capaz de atender unicamente, se assim desejável, ao objetivo de prestação de serviço público de destinação final dos RSU e operação de aterro sanitário que serve o consórcio intermunicipal.

Levando isso em consideração, o Departamento de Resíduos Sólidos (DRS) da Superintendência de Desenvolvimento de Recursos Hídricos e Saneamento Ambiental (SUDERHSA) do Estado do Paraná realizou um estudo de regionalização da destinação final dos RSU no qual os resíduos gerados nos municípios partícipes do consórcio são destinados a um aterro regional localizado dentro do território do respectivo consórcio.

A destinação final dos RSU em aterros sanitários regionais viabiliza o rateio dos custos operacionais e administrativos com ganhos de escala, a contratação de serviços profissionais de operação do aterro, a otimização do uso de máquinas e equipamentos, a redução do número de áreas utilizadas, a redução de possíveis focos de contaminação ambiental e, consequentemente, a concentração das ações de fiscalização do órgão ambiental competente. Vaz (1997 apud IBGE, 2005) cita o aumento da oferta de serviços públicos à população e o aumento do poder de diálogo e negociação dos municípios na resolução de problemas locais. No caso dos municípios de pequeno porte, essas vantagens adquirem ainda mais relevância.

Por outro lado, vários fatores podem influir na verificação prática dos resultados do planejamento realizado pelo estudo, destacandose como barreira o fator político-partidário e, como fatores incentivadores, a atuação do Ministério Público e do órgão de fiscalização ambiental competente.

Relatam-se aqui os critérios de planejamento e os resultados do estudo realizado, tendo como base critérios demográficos (população urbana), logísticos (malha viária existente e distância entre sedes urbanas, da Secretaria Estadual de Transportes) e outras diretrizes utilizadas como referência (como distância máxima de 50 km, gestão por unidades hidrográficas), tendo como pressuposto de planejamento a não necessidade de estações de transbordo.

\section{Metodologia}

A análise para a formação dos consórcios observou as seguintes diretrizes de planejamento:

- distância máxima de 50 km entre as sedes: corresponde à máxima distância viária das sedes urbanas dos municípios do consórcio até a sede urbana do município em cujo território se localizaria $\mathrm{o}$ aterro intermunicipal. $\mathrm{O}$ valor de $50 \mathrm{~km}$ foi definido visando a limitar em uma hora o tempo gasto pelo caminhão coletor para transportar os resíduos até o aterro, considerando-se uma velocidade média de $50 \mathrm{~km} / \mathrm{h}$;

- um aterro regional por grupo de municípios: os municípios que atualmente depositam seus resíduos em aterro sanitário devidamente licenciado poderão passar a destiná-los ao aterro regional ao fim da vida útil do aterro que hoje utilizam. Já aqueles que depositam seus resíduos inadequadamente, poderiam passar a destiná-los imediatamente ao aterro regional;

- maior número de municípios por sede operacional: significa associar a um consórcio todos os municípios cuja sede urbana esteja até $50 \mathrm{~km}$ de distância da sede operacional, proporcionando a redução do número de aterros regionais a serem implantados;

- evitar a transferência de resíduos entre bacias hidrográficas: as sedes urbanas dos municípios do consórcio formado devem estar localizadas na mesma bacia, exceto quando não houver, para o município com sede urbana na bacia vizinha, outra sede operacional mais próxima à qual associá-lo;

- manter a configuração dos Consórcios Intermunicipais de Aterros Sanitários já existentes: realizado na medida do possível, visando a aproximar o estudo da realidade. No Paraná, havia, até o início do estudo, cinco consórcios intermunicipais de aterros sanitários em operação.

Vale ressaltar que não existe uma hierarquia de diretrizes. Todas foram levadas em consideração, havendo casos particulares em que algumas adquiriram maior relevância no mapeamento dos consórcios intermunicipais em potencial.

Para realizar o estudo, foram utilizados dados de população urbana (IBGE, 2002) e sobre a malha viária (distância viária entre sedes municipais e tipo de asfaltamento) em conjunto com um mapa gerado com sobreposição em camadas dos dados da malha viária do Estado do Paraná ${ }^{1}$, da localização das unidades hidrográficas estaduais ${ }^{2}$, da localização georreferenciada da divisão político-administrativa dos municípios e suas respectivas sedes urbanas ${ }^{3}$.

Para a realização do estudo, definimos como sede operacional os municípios em cujo território estaria localizado o aterro regional em função da presença de interligação viária com os demais municípios do consórcio na menor distância possível e em vias com melhor condição de trafegabilidade.

\section{Resultados}

O estudo resultou na identificação de 58 sedes operacionais que centralizariam a destinação final dos RSU de 377 municípios mediante a formação dos consórcios intermunicipais, compreendendo 97,3\% do total da população urbana do Estado. 
Tabela 1 - Consórcios formados classificados por intervalo de população urbana total

\begin{tabular}{|c|c|c|c|c|}
\hline $\begin{array}{l}\text { Intervalos de população } \\
\text { urbana total }\end{array}$ & Consórcios & Municípios & População urbana total & $\begin{array}{l}\text { População urbana total do } \\
\text { Estado do Paraná (\%) }\end{array}$ \\
\hline$X \leq 10.000$ & 2 & 7 & 15.279 & 0,2 \\
\hline $10.000<X \leq 30.000$ & 14 & 49 & 264.739 & 3,4 \\
\hline $30.000<X \leq 50.000$ & 9 & 43 & 341.820 & 4,4 \\
\hline$x>70.000$ & 21 & 188 & 6.239 .607 & 80,1 \\
\hline Subtotal & 58 & 377 & 7.575 .266 & 97,3 \\
\hline Não consorciados & - & 22 & 210.368 & 2,7 \\
\hline Total & 58 & 399 & 7.785 .634 & 100,0 \\
\hline
\end{tabular}

Dos 58 consórcios intermunicipais formados, 33 possuem população urbana superior a 50 mil habitantes e 25 são consórcios intermediários, cuja população urbana total é inferior a 50 mil habitantes.

Os consórcios com população urbana acima de 50 mil habitantes atenderiam a $89,3 \%$ da população urbana do Estado, compreendendo 278 municípios. Por sua vez, os consórcios intermediários atenderiam a $8 \%$ da população urbana, totalizando 99 municípios.

Vinte e dois municípios não foram associados a nenhum consórcio em função da distância de transporte, mesmo com uma tolerância para valores ligeiramente superiores a $50 \mathrm{~km}$.

A Tabela 1 sintetiza os resultados obtidos por intervalo de total de população urbana por consórcio intermunicipal em potencial, o número de municípios compreendidos e a população urbana equivalente em relação ao seu total no Estado.

No site eletrônico da Superintendência de Desenvolvimento de Recursos Hídricos e Saneamento Ambiental (SUDERHSA) (www. suderhsa.pr.gov.br), clicando no ícone "Saneamento ambiental", seguido de "Programa de resíduos sólidos urbanos", visualiza-se o link "Consórcios intermunicipais de resíduos sólidos urbanos". Este último link leva à página onde se encontram disponíveis para download: 1) modelo de termo de referência visando a orientar os municípios interessados na formação de consórcios intermunicipais; 2) anexo do termo de referência, com os resultados do estudo prospectivo relacionando as sedes operacionais e dados descritivos do consórcio do qual a sede faz parte; 3) mapa estadual em que se visualizam os consórcios do estudo prospectivo.

Com exceção do consórcio intermunicipal de Curitiba, foi possível manter a composição dos outros quatro consórcios pré- existentes, encontrando sedes operacionais às quais associar os municípios vizinhos. No consórcio intermunicipal de Curitiba, foram adicionados os municípios de Bocaiúva do Sul e Rio Branco do Sul pelo fato de ser Curitiba a sede operacional mais próxima e dentro do limite da distância máxima de $50 \mathrm{~km}$. Em caso contrário, esses municípios não teriam sido associados a nenhum consórcio.

\section{Conclusões}

O modelo proposto sugere que a implantação de 58 aterros regionais que receberiam os RSU gerados nos territórios dos 58 consórcios intermunicipais poderia substituir a implantação e a operação de 377 aterros se cada município tivesse seu próprio aterro.

No Paraná, a expectativa é de que o estudo auxilie na coordenação e na orientação das iniciativas dos municípios que têm interesse em formar um consórcio intermunicipal para viabilizar a destinação final adequada dos RSU. O conhecimento obtido durante a elaboração do estudo permitiu a elaboração de um termo de referência, o qual serve como mais um instrumento visando a facilitar esse objetivo da melhor forma possível.

A implantação dos aterros sanitários de modo algum deve ser uma iniciativa isolada na busca pelo gerenciamento eficaz dos RSU. A destinação final é apenas uma parte do ciclo, cujo gerenciamento adequado deve contemplar ações visando à redução, à reutilização e à reciclagem dos resíduos gerados. Quanto menos resíduos forem destinados ao aterro sanitário, por mais tempo ele poderá atender à necessidade de confiná-los de modo seguro, evitando a utilização de novas áreas e reduzindo riscos à saúde humana e ao meio ambiente. 


\section{Referências}

BRASIL. Decreto federal $n^{\circ} 6.017$, de 17 de janeiro de 2007. Regulamenta a lei $n^{\circ} 11.107$, de 6 de abril de 2005, que dispõe sobre normas gerais de contratação de consórcios públicos. Diário Oficial da União, Brasília, DF, n. 13, p. 1-4, 18 de janeiro de 2007

INSTITUTO BRASILEIRO DE GEOGRAFIA E ESTATÍSTICA (IBGE). Censo Demográfico, 2000. Rio de Janeiro, 2002. [On-line]. Disponível em: <http://www.ibge.gov.br/home/estatistica/populacao/censo2000/ default.shtm> Acesso em: 15 nov. 2006.
Perfil dos municípios brasileiros: meio ambiente, 2002. Rio de Janeiro, 2005. [On-line]. Disponível em: <www.ibge.gov.br> Acesso em: 3 set. 2007

. Pesquisa nacional de saneamento básico, 2000. Rio de Janeiro, 2002. [On-line]. Disponível em: <http://www.ibge.gov.br> Acesso em: 3 set. 2007.

PARANÁ. Secretaria Estadual de Transportes. Paraná logística e multimodalidade. CD-ROM. 